\title{
OS BATISTAS E $O$ CRESCIMENTO EVANGÉLICO
}

THE BAPTIST AND EVANGELICAL GROWTH Adair Nelo Pereira ${ }^{44}$ Maria do Socorro Freire de Sá ${ }^{45}$

\footnotetext{
${ }^{44}$ Bacharel em Teologia pela Faculdade de Teologia da Universidade Metodista de São Paulo.Email: adair_raca@hotmail.com

${ }^{45}$ Bacharel em Teologia pela Faculdade de Teologia da Universidade Metodista de São Paulo.
} 


\section{RESUMO}

O presente artigo traz um estudo sobre o crescimento evangélico mostrado nos últimos Censos do IBGE, com destaque para os evangélicos de missão, tentando explicar por que dos protestantes históricos de missão só os batistas crescem. Se fará uma comparação entre os números das pessoas que se declararam batistas com os membros das demais igrejas de missão, principalmente a presbiteriana, metodista e congregacional. Será descrita a história, princípios e como se deu a relação das igrejas evangélicas de missão, entre si e com os católicos. E quais aspectos diferenciam os batistas das demais igrejas, e o quanto isso influenciou e influencia no seu crescimento numérico.

\section{PALAVRAS-CHAVES}

Censo; religião; evangélicos; batistas; governo; igrejas.

\section{ABSTRACT}

This article presents a study on the evangelical growth shown in the last IBGE Censuses, especially evangelicals of mission, trying to explain why of the historical protestant missionaries only the Baptists grow. A comparison will be made between the numbers of people who have declared themselves Baptists with members of other mission churches, especially the Presbyterian, Methodist, and Congregational churches. It will describe the history, principles and how the relationship of the evangelical churches of mission with each other and with the Catholics. And what aspects differentiate Baptists from other churches, and how much that has influenced and influence their numerical growth.

\section{KEYWORDS}

Census; religion; evangelicals; Baptists; government; churches. 


\section{INTRODUÇÃO}

Quando em junho de 2012, o IBGE divulgou os números sobre religião do último Censo, algumas tendências se mantiveram, como o declínio do catolicismo e o crescimento evangélico, que continuou acelerado como nos últimos Censos. Mas para quem se aprofunda nos Censos do IBGE em busca dos detalhes, descobre alguns números que causam surpresas ${ }^{46}$.

De acordo com o Censo de 2010, o grupo evangélico de missão se mantém estável. Mas precisamos entender o que levou os batistas a crescerem e as demais igrejas não, os presbiterianos, congregacionais, luteranos e metodistas. Nesse artigo pretendemos explicar quais as diferenças dos batistas em relação as demais igrejas evangélicas de missão, para que tenha tido resultados diferentes delas. Dessa forma organizamos o estudo em três partes.

Na primeira parte deste artigo: os números do IBGE e o crescimento evangélico, iremos detalhar os números do Censo, identificando cada grupo evangélico, seu desempenho e suas principais características, relacionando alguns pontos diferentes e de destaque dos batistas.

Já a segunda parte: origem e desenvolvimento dos batistas, traz um pouco da sua história, como também suas relações com os católicos e demais denominações históricas de missão. Será exposto também detalhes sobre as diversas igrejas batistas no Brasil.

A terceira parte: batistas, identidade e diferencial, buscamos explicar quais aspectos relevantes os batistas têm que justifiquem esse crescimento, tanto os aspectos históricos como nos dias de hoje.

Destarte, iremos avaliar se há pontos diferentes e/ou comuns entre os evangélicos de missão, que nos leve a explicar o porquê desse contínuo crescimento batista, e que possa direcionar outros estudos futuros.

\footnotetext{
${ }^{46}$ Como por exemplo o grande número de "evangélicos não determinados", que eram 581 mil em 2000, e passaram dos 9 milhões em 2010 (JACOB et al., 2013, p.10).
} 


\section{OS NÚMEROS DO IBGE E O CRESCIMENTO EVANGÉLICO ${ }^{47}$}

\subsection{CENSOS DO IBGE E O PROTESTANTISMO NO BRASIL}

Desde a chegada dos primeiros protestantes ao Brasil em $1810^{48}$, a sua expansão tem sido contínua. Mas nos últimos Censos (1980-2010) esse crescimento tem sido maior em números absolutos. Os evangélicos ${ }^{49}$, como são conhecidos atualmente, eram cerca de 7,9 milhões em 1980 e em 2010 já representavam $22,2 \%$ da população brasileira, com cerca de 42,3 milhões $^{50}$. Esse crescimento no início do século XXI, se deve em grande parte ao movimento pentecostal nascido nos Estados Unidos no início do século XX (MARIANO 2005, p.10).

Os pentecostais, que inclui aqui os neopentecostais ${ }^{51}$, é o grupo religioso que tem chamado a atenção pelo seu crescimento, eram 3,2\% em 1980 passando 13,3\% da população brasileira em 2010, chegando a mais de 25 milhões de pessoas. Os pentecostais em 1980 representavam 49\% dos evangélicos, em 2010 passaram para $60 \%$. Dentro os pentecostais brasileiros, a maior denominação é a Assembleia de Deus com quase $50 \%$ dos fiéis (MARIZ; GRACINO JR 2013, p. 162; JACOB et al, 2013, p.10-17).

\footnotetext{
${ }^{47}$ Evangélicos, no Censo 2010 designa um grande grupo religioso, divididas entre 3 subgrupos: evangélicos de missão; evangélicos de origem pentecostal; e evangélicos não determinadas. Para ver relação detalhada consultar anexo 3 deste Censo no site do IBGE: uww.ibge.com.br.

${ }^{48} \mathrm{Em} 1810$ os ingleses tiveram permissão para entrar e realizar seus cultos, mas de maneira restrita. MENDONÇA, Antônio Gouvêa e FILHO, Prócoro Velasques. Introdução ao protestantismo no Brasil. 2 ed. São Paulo, Loyola, 2002, p.12. Os primeiros registros de protestantes no Brasil colônia se dá em 1557 com Huguenotes franceses. ver MATOS, Alderi Souza de. Breve história do protestantismo no Brasil. Goiânia, v.3, n.1, 2011. Disponivel em: $<$ http://uww.faifa.edu.br/revista>. p. 4.

${ }^{49}$ O termo evangélico designa todas as igrejas e denominações cristãs nascidas ou de descendência da reforma protestante, não só as igrejas protestantes históricas de imigração e missão, como também as Pentecostais. Entre elas: Congregação Cristã, Assembleia de Deus, Evangelho Quadrangular, Brasil para Cristo, Deus é amor, Casa da Benção, Universal do Reino de Deus, etc. Conforme MARIANO 2005, p.10.
}

http://seriesestatisticas.ibg e.gov.br/s eries.asp $x ? n o=10 \& o p=0 \& v \operatorname{cod}$ igo $=P O P 60 \& t=p o$ pulaca o-religiao-populacao-pres ente-residente.

${ }^{51}$ Para mais detalhes sobre os neopentecostais ver MARIANO, Ricardo. Neopentecostais: Sociologia do novo pentecostalismo no Brasil. 2 ed. São Paulo: Edições Loyola, 2005. 
Além dos pentecostais, dois outros grupos dentro dos evangélicos merecem atenção. Primeiro os chamados "evangélicos não determinados", que nem eram citados no Censo de 1980, em 2010 representavam 4,8\%, mais de 9 milhões de pessoas; e por último os "sem religião", que eram apenas 1,6\% da população brasileira, e no censo de 2010 chegaram a 8\%, mais de 15 milhões de pessoas (JACOB, 2010).

Por outro lado, percebe-se um declínio do catolicismo e do protestantismo histórico no Brasil. Os católicos em 1980 eram $89,2 \%$ da população brasileira, em 2010 caiu para 64,6\%. Sendo que na década de 2000 para 2010, é a primeira vez que os católicos diminuem em números absolutos, saem de 125,5 para 123,3 milhões (MARIANO, 2013, p 1).

\subsection{PROTESTANTES HISTÓRICOS E O CRESCIMENTO BATISTA}

E os protestantes históricos, como se saíram nos últimos censos do IBGE? Eles cresceram apenas 10,8\% de 2000 a 2010, inferior a década anterior que chegou a 58,1\% (MARIANO, 2013, p.124). Pelo último censo os evangélicos de missão eram $4,0 \%$, um pouco maior que os 3,4\% em 1980. Em números absolutos cresceram $91 \%$ em 40 anos (1980-2010), pouco se compararmos com os pentecostais $556 \%$ e os sem religião $685 \%$.

Mas um fato nos chamou a atenção, e é o que queremos investigar neste artigo: por que dos protestantes históricos só os batistas cresceram? Quais foram as razões? Temos, atualmente, vários grupos dentro dos batistas, podemos citar: a Convenção ${ }^{52}$ Batista Brasileira, Convenção Batista Nacional, Convenção das Igrejas Batistas Independentes, Convenção Batista Renovada, Associação das Igrejas Batistas Regulares do Brasil, Comunhão Batista Bíblica Nacional, e muitas outras igrejas batistas independentes que não estão ligadas a nenhuma convenção ou associação. Também é necessário entender se todos eles também crescem separadamente.

\footnotetext{
${ }^{52}$ Convenção é a cooperação de igrejas que defendem os mesmos princípios e doutrinas de uma denominação, com o objetivo de unir forças para se expandir em frentes que não seriam possíveis sozinhas, como educação e missões.
} 
As regiões mais representativas dos batistas são as regiões Nordeste com $63,55 \%$ do total de protestantes de missão e o Sudeste com $55,45 \%$. Exatamente as regiões onde começou a evangelização pelos missionários americanos no fim do século XIX e início do séculoXX. Os batistas são menores na região Sul, apenas $15,32 \%$, lá os Luteranos representam $55,9 \%$ do protestantismo de missão, apesar dele em maioria serem identificados como protestantismo de imigração(CAMPOS, 2013, p. 140-148, 150).

Comparando os censos de 2000 e 2010, os batistas saem de 3.162.691 para 3.723.853 de membros, um crescimento de $17,74 \%$, maior que o da população que cresceu $12,29 \%$ no mesmo período. Enquanto as demais igrejas denominadas históricas de missão todas caem em números absolutos, Luteranos perderam 62.647 membros, os Presbiterianos 59.855, e os Congregacionais 39.245. Os Metodistas só perderam 25 membros, pelos números do IBGE. Outras evangélicas de missão, que estão inseridas Anglicanos e Episcopais, perderam 3.558 membros.

Neste artigo deixaremos de fora os Adventistas, que apesar do IBGE colocar dentro do grupo evangélicos de missão, na maioria da bibliografia consultada os autores não os definem como protestantes, nem eles mesmos se definem como evangélicos. ${ }^{53}$

Retirando os adventistas, os batistas são $61 \%$ dos protestantes históricos, antes 55\% em 2000. Mas esse crescimento não é recente:

A partir do início do século $X X$, os batistas começaram a apresentar crescimento surpreendente, passando à frente das igrejas de origem missionária. Em 1889 eles somavam apenas 312 fiéis em quatro congregações. Partiram daí para se tornarem a maior igreja tradicional de origem missionária (MENDONÇA, 2002, p. 43).

Mas será que todos os grupos batistas crescem? No caso das igrejas batistas brasileiras, elas estão divididas em várias

\footnotetext{
${ }^{53}$ ANTONIAZZI, Alberto. Porque o panorama religioso mudou tanto? Revista Horizonte, $v$ 3, n 5, Belo horizonte, 2004. p. 29. Cf. Tb. CAMPOS, 2008, p. 27.
} 
convenções, a principal delas é a Convenção Batista Brasileira, fundada em 1907, e que conta hoje com 13.436 igrejas e cerca de 1,7 milhões de membros. A segunda é a Convenção Batista Nacional com 2.882 igrejas e cerca de 413 mil membros ${ }^{54}$. Esses números são desatualizados, passadas por suas igrejas filiadas. Provavelmente abaixo da realidade. Somando estas duas convenções, elas representam $57 \%$ dos batistas brasileiros.

A Convenção Batista Brasileira (CBB) cresceu percentualmente mais que os evangélicos na última década. Eram 944.515 em 2002 e 1.536 .298 em 2012 (62,65\% contra 61,59\%) $)^{55}$. Estima-se, segundo informações da CBB, que estejam próximos a 2 milhões, para isso a CBB está atualmente fazendo um censo junto às igrejas filiadas, para saber qual o total de membros ligados a essa convenção. Vale ressaltar que, nessa contagem só são válidas pessoas que são batizadas, estando de fora as crianças (os batistas não aceitam e não praticam batismos de crianças), os novos convertidos e os congregados não batizados.

\subsection{AGRESSIVIDADE EVANGÉLICA E ANTICATÓLICA}

Um dos autores mais antigos a estudar o protestantismo no Brasil, é o francês Émile G. Léonard (2002). Ele cita a força evangelizadora que acompanhou os muitos missionários vindos das várias missões das diferentes igrejas protestantes dos estados Unidos, que se estabeleceram principalmente em Santa Bárbara d'Oeste, fugindo de momento conturbado devido a Guerra de Secessão (1861-1865), e aproveitando o ambiente progressista que o Brasil vivia na época (LÉONARD, 2002, p. 84-85)

Da missão batista, há destaque para dois grandes missionários. O reverendo William Bagby, que passou de 1881 a 1935 abrindo igrejas na Bahia e Rio. Sua dedicação a obra missionária se destacou na época. O outro era o W. E. Entzminger,

\footnotetext{
${ }^{54}$ São dados obtidos nos sites dessas convenções, não sendo dados exatos, pois as mesmas estão fazendo um censo de seus membros em 2016/2017. Disponível em: http://batistas.com/artigos/cbb-realizara-o-censo-batista-2016, acesso em: 07 set 2016. Cf. Tb. http://cbn.org.br/downloads/historiadosbatistasnacionais.pdf, acesso em: 07 set 2016. As demais convenções citadas no ponto 1.2 não disponibilizam números em seus sites, $e$ não retornaram e-mails.

${ }^{55}$ Livro da Convenção Batista Brasileira 2013. Rio de Janeiro, p. 49-50.
} 
que chegou 10 anos após Bagby, mas fez grande obra, fundando várias igrejas em Pernambuco e no Rio de Janeiro. O resultado dessas primeiras empreitadas, foi que em 1906 os batistas contavam com mais de 80 igrejas e 4.000 membros, um crescimento considerável principalmente na Bahia, onde tinham 30 igrejas (LÉONARD, 2002, p.86-89, 104).

Mas qual seria esse segredo, já no início do século XX? Outro grande estudioso do protestantismo no Brasil, Mendonça, nos dá algumas pistas.

O crescimento batista, apesar de suas dificuldades iniciais, pode ser justificado por uma série de fatores. $O$ primeiro deles foi a agressividade evangélica e anticatólica revelada muito cedo pelos batistas, numa época em que as demais igrejas procuravam agir moderada e diplomaticamente em face da religião dominante. A ação mais corajosa dos batistas fez com que sofressem reações muito fortes; em compensação levou-os à conquista de mais adeptos (MENDONÇA, 2002, p. 43-44).

Os batistas já com os primeiros missionários, foram ousados, e nada diplomáticos, sua missão era converter o povo, assim como os "hereges católicos". Mas sofreram as consequências, com as diversas perseguições ocorridas, mas que acabou gerando frutos de peso, como o ex-padre Antônio Teixeira de Albuquerque, considerado o primeiro batista brasileiro, e responsável em maior parte pelo discurso anticatólico, condensado na publicação "Três razões porque deixei a igreja católica" (CRABTREE, 1962, p.70-71).

O segundo fator é a evangelização direta, não tanto pela educação. Enquanto os presbiterianos e metodistas se preocupavam com a educação da elite brasileira, os batistas, que também tinham essa preocupação, se voltaram para a evangelização das camadas mais pobres, que aparentemente eram menos comprometidas, mas que a história e os números mostram ao contrário. Foi a camada mais pobre da população que impulsionou os pentecostais (MENDONÇA, 2002, p. 40; MARIANO, 2013, p.125). 
O terceiro fator citado pelo professor Antônio Gouvêa Mendonça, é com relação a eclesiologia mais simples, onde o novo convertido já se integra rapidamente ao contexto da igreja. O quarto fator é a ética mais rigorosa perante a sociedade, que torna a identidade batista mais segura. E o quinto fator citado é batismo, que semelhantemente aos pentecostais é por imersão, tornando um rito marcante na vida dos novos membros, em alguns casos acontecem em rios ou lagos.

\subsection{GOVERNO CONGREGACIONAL E COOPERAÇÃO DAS IGREJAS}

Os batistas adotam dois princípios que se destacam, autonomia da igreja local e a cooperação dessas mesmas igrejas em torno de uma convenção regional e nacional facultativa (ROCHA; ZORZIN, 2012, p.9).

O governo congregacional defendido desde as origens inglesas, é um forte diferencial dos batistas, diferente dos presbiterianos e metodistas.

Todos os membros de uma igreja batista gozam dos mesmos privilégios e direitos. O seu governo é pura democracia. Não há distinção entre pastores e os membros quanto à autoridade eclesiástica. Não há hierarquia na igreja batista. A influência de um membro depende de sua capacidade, cultura e espiritualidade. É a igreja e não o pastor que tem a última palavra na solução de qualquer problema. Todas as igrejas batistas são autônomas e, portanto, independentes de todas as demais. Nenhuma associação, assembleia, convenção ou junta pode impor a sua autoridade à igreja local. (CRABTREE, 1962, p.29).

A autonomia que as igrejas batistas têm, e a sua adesão voluntária a convenção, tem contribuído para a expansão dos batistas no Brasil. Apesar do governo descentralizado dos Batista, eles têm uma doutrina centralizada e bem definida e preza muito por questões éticas. Isso tem atraído muitas pessoas, principalmente os decepcionados com as neopentecostais. Esse tradicionalismo doutrinário junto com a contextualização das 
igrejas locais mantém um consistente crescimento (ARAÚJO; REFKALEFSKY, 2009, p.7-8).

Esse espírito de cooperação traz em seu escopo o mesmo modelo da convenção batista do sul dos Estados Unidos. Sendo um dos objetivos principais para a criação da Convenção Batista Brasileira em 1907, a necessidade de aumentar o trabalho missionário tanto no Brasil como no exterior. Sendo criadas na época a Junta de Evangelização Nacional e a Junta de Missões Estrangeiras, atualmente conhecidas respectivamente, como, Junta de Missões Nacionais (JMN) e Junta de Missões Mundiais (JMM).

A liberdade das igrejas tem dado mais dinamismo a comunidade local, facilitando sua adaptação ao contexto da região em que estão inseridos. Não ficam engessadas, esperando um "manual eclesiástico" para tomar algumas decisões de cunho local. Sendo assim, o "dinamismo, a capacidade de mobilização e à sua estratégia de evangelização" são características essenciais para a expansão (ANTONIAZZI, 2004, p.27).

Percentualmente os batistas caem do início ao final do século $X X$ se comparado ao total de evangélicos, eram $30 \%$ em 1930 caindo para 8,8\% em $2000^{56}$ (CAMPOS, 2008, p.26). Mas dentro do grupo históricos de missão representam 61\% em 2010. Conclui Campos:

Os batistas, talvez pela sua agressiva maneira de fazer propaganda ou pela forma congregacional de organizar as suas congregações locais, obtiveram um melhor equilíbrio entre governo local, o poder das associações estaduais, e o controle indireto e não intervencionista de uma convenção nacional (CAMPOS, 2008, p.26).

Realmente, os batistas mostraram ao longo dos anos, possuidores de uma grande organização denominacional, boa parte herdada das missões do sul dos Estados Unidos, sempre

${ }^{56}$ Censo IBGE 2010. 
voltada para aumentar o número de igrejas no país e manter a sua identidade, a identidade batista ${ }^{57}$.

\subsection{CONFLITOS E PROSELITISMO}

Mas nem tudo são flores, existem muitos conflitos e alguns cismas na história batista, como o ocorrido na década de 60 , ocasionada pelo movimento de renovação espiritual, que deu origem a Convenção Batista Nacional. Também tem se visto poucos resultados apesar de grande mobilização das igrejas.

Os batistas brasileiros apresentam, ao longo de sua história, muitos conflitos e dissensões, conservando, entretanto, como já notamos, admirável identidade. O esforço evangelístico tem continuado através de campanhas intensas e extensas, embora, segundo levantamentos feitos, indiquem muita energia e poucos resultados efetivos. Apesar da dificuldade de se obter dados seguros, os batistas parecem ser a única igreja tradicional de origem missionária que ainda cresce, em taxa relativamente pequena (MENDONÇA, 2002, p.44).

Além dos conflitos internos, o início dos batistas no Brasil também é marcado de conflitos com outras denominações. Ocupando os mesmos espaços, a concorrência entre as denominações presbiteriana, congregacional, metodista e batista se acirraram, e acabaram ocasionando transferência de membros de uma para as outras. E nesse ponto os batistas levaram vantagem. Grande parte ocasionado pelo seu governo congregacional, que dava pleno poder as congregações locais na admissão de novos membros, assim também como sua forma de batismo em relação a essas denominações, que dava um caráter mais espetacular (LÉONARD 2002, p. 140-142).

${ }^{57}$ Doutrina, princípios e valores defendidos pelos batistas. 


\section{ORIGEM E DESENVOLVIMENTO DOS BATISTAS}

\subsection{INGLATERRA, ESTADOS UNIDOS E BRASIL}

Um povo chamado batista ${ }^{58}$, como assim denomina-se os evangélicos brasileiros que têm raiz na Inglaterra do século XVII, e que teve início na Holanda em 1609. Nesse ano surgiu a primeira igreja com características específicas do que vai ser conhecida como igreja Batista. Essa igreja tinha a liderança do pastor inglês John Smyth e de seu financiador o advogado Thomas Helwys (AZEVEDO,1996, p. 77).

Alguns princípios têm sido defendidos pelos batistas desde a época da reforma anglicana, principalmente a liberdade do indivíduo e a separação entre a igreja e o estado, sendo essa última uma herança dos puritanos ingleses. Inconformados com a ligação de alguns grupos de crentes com a igreja oficial da Inglaterra, e sofrendo perseguições, um grande grupo migrou para a Holanda e outro para a América do Norte. Esse segundo grupo desembarcou na costa dos Estados Unidos em 1620, no estado conhecido hoje como Massachusetts, dando início a uma região que é conhecida até hoje como Nova Inglaterra, e tem como uma de suas principais cidades Boston (PEREIRA, 1979, p. 79).

É nos Estados Unidos que surgem as convenções batistas missionárias do Sul e do Norte, inspiradas no pioneirismo do pastor batista inglês William Carey ${ }^{59}$. Os congregacionais foram os primeiros a enviar missionários, e logo em seguida as missões Batistas também enviaram missionários para a Índia e África. Mas é da convenção batista do Sul, da Junta de Richmond, que são enviados os primeiros missionários americanos ao Brasil (PEREIRA, 1979, p.84-87).

\footnotetext{
${ }^{58}$ Os batistas, uma das igrejas da reforma, se autodenominasse "um povo chamado batista". Visto em: MENDONÇA, Antônio Gouvêa e FILHO, Prócoro Velasques. Introdução ao protestantismo no Brasil. 2 ed. São Paulo, Loyola, 2002. Também é o título do livro sobre a história dos batistas, escrito pelo Prof. Dr. Zaqueu Moreira de Oliveira (OLIVEIRA 2011).

59 Guilherme Carey, também conhecido como William Carey, pastor batista inglês, conhecido como "pai" de missões modernas. OLIVEIRA, Zaqueu Moreira. Um povo chamado batista: História e princípios. 2. Ed. Revista e corrigida. Recife: Kairós Editora, 2011, p. 72-76.
} 
Em 1850 os batistas do sul dos Estados Unidos manifestaram o desejo de enviar missionários a América do Sul, várias cidades como destino, entre elas a capital do império Rio de Janeiro. Mas o domínio católico, é uma das dificuldades levantadas, dessa forma o foco o trabalho missionário se mantém na África. Mas um relatório de 1859 apontam condições favoráveis para missões no Brasil, mas o conteúdo é recheado por um discurso anticatólico.

(...) o país é novo, no sentido que está emergindo das trevas do domínio do papa e de Portugal, e está tornando lugar entre as nações progressistas da terra. O povo brasileiro não tem o evangelho e a igreja católica não satisfaz às necessidades espirituais. (CRABTREE, 1962, p.57).

O primeiro missionário batista americano no Brasil, foi Thomas Jefferson Bowen, chegou em 1860 juntamente com sua esposa Lurenna. Bowen foi missionário da Convenção Batista do Sul dos Estados Unidos na Nigéria. Após alguns anos na África teve que retornar aos Estados Unidos para cuidar de sua saúde ${ }^{60}$. A Junta de Missões acabou os impedindo de retornar a Nigéria. Bowen declara que não deve ter sido só por causa da saúde, mas "por ser um missionário que contestava e desafiava as políticas missionárias" (SOUZA 2012, p. 17).

No Brasil Bowen continua tendo problemas com sua saúde, mas a falta de apoio agravou em muito sua estadia no Brasil, o fazendo retornar com sua esposa ao Estados Unidos, para nunca mais atuar como missionário (SOUZA 2012, p. 24).

Bowen não fundou uma igreja no Brasil, mas o Pastor Richard Ratcliff, que foi o primeiro pastor e um dos fundadores da primeira igreja batista em solo brasileiro, foi fruto de uma de suas pregações, indiretamente Bowen teve importante participação no início do trabalho batista no Brasil (SOUZA, p. 28-29).

\footnotetext{
${ }^{60}$ Uma breve biografia de Bowen se encontra em, SOUZA, Alverson. Thomas Jefferson Bowen: o primeiro missionário batista no Brasil. Rio de Janeiro: Editora Novos Diálogos, 2012.
} 
Com isso o estabelecimento da primeira igreja Batista61 em solo brasileiro é fruto da imigração de colonos americanos para o Brasil, fugindo das consequências da Guerra da Secessão que deixou grandes estragos tanto no Norte como Sul dos Estados Unidos. Esses colonos $^{62}$ encontram no Brasil uma oportunidade de reconstrução. O Brasil atravessava um período de progresso, e com a permissão do império, uma boa parte desses imigrantes escolhem São Paulo. Um bom grupo teve sucesso na cidade de Santa Bárbara, na época pertencente a província de São Paulo (CRABTREE, 1962, p.59).

Depois de vários apelos das lideranças batistas, em 1881 a junta de Richmond elevou a condição de "Missão Brasileira", nomeando seus pastores como missionários, sendo substituídos depois pelo casal William e Anne Bagby. Apesar de seu caráter restrito, essas congregações tiveram papel essencial para a expansão do evangelho e da denominação batista no Brasil, foi dali que saíram os cincos fundadores da igreja de Salvador, considerada com a Primeira Igreja Batista do brasil63. Além do casal Bagby, foram a Bahia o casal Zacarias e Kate Taylor e o ex-padre Antônio Teixeira de Albuquerque (1840-1877) ${ }^{64}$, responsável pela maioria do discurso anticatólico.

Depois de Santa Bárbara e Salvador, os batistas se expandem para o Rio de Janeiro. Recheado de um discurso evangelístico anticatólico, nem tudo foi fácil para o início dos batistas no Brasil. Apesar da abertura dos campos em vários estados do Brasil, muitas lutas e perseguições foram enfrentadas pelos missionários e pastores. Os cultos na época eram realizados

\footnotetext{
${ }^{61}$ Primeira Igreja Batista no Brasil, fundada em 10 de setembro de 1871, na cidade de Santa Barbara, SP.

${ }^{62}$ A colônia estabelecida em Santa Bárbara era composta por famílias de confissão das principais denominações cristãs históricas: metodistas; presbiterianos; e batistas.

${ }^{63}$ Organizada em 15 de outubro de 1882 a Primeira Igreja Batista em Salvador ficou conhecida como Primeira Igreja Batista do Brasil, apesar de ter sido a terceira igreja batista organizada no país; OLIVEIRA, Zaqueu Moreira de. Princípios e práticas batistas, uma abordagem histórica aplicada aos nossos dias. 4. Ed. Revista e ampliada. Recife: Kairós Editora, 2014.

${ }^{64}$ Antônio Teixeira de Albuquerque é considerado o primeiro crente batista brasileiro, apesar de seus primeiros contatos com a igreja metodista, conforme CRABTREE, A.R. História dos Batistas do Brasil: até o ano de 1906. Casa Publicadora Batista, Rio de Janeiro, 1962. p. 70-71.
} 
em casas e templos que não tinham nenhuma semelhança com as igrejas católicas, não era permitido que os locais de culto protestante tivessem algo externo que os identificasse como igreja. Destarte, os batismos normalmente eram realizados em local público, trazendo revolta das autoridades e padres locais. (OLIVEIRA, 2011, p.109-110).

As perseguições foram mais intensas no final do séculoXIX e início do $X X$, atingiram desde os primeiros missionários americanos, como a muitos missionários e fiéis no Brasil, sendo Pernambuco o palco das maiores perseguições no início do século XX (OLIVEIRA 2011, p.109-119).

\subsection{AVANÇO E DESAVENÇAS DOS BATISTAS BRASILEIROS}

Com o avanço batista começa a surgir os problemas. Já na $2^{a}$ década do século $X X$, surgia a primeira desavença na denominação, foi o movimento conhecido como Radical65. Originário do Seminário do Norte, foi um questionamento da influência americana na gestão brasileira. Despertando na época a vontade de "andar com as próprias pernas".

Logo houve exclusões de membros e igrejas, que se uniram em várias outras associações, que teve como principal a Associação Batista Brasileira, que foi dissolvida em 1938 e agregada a CBB. Existiu um segundo momento dessa radicalização, onde esse movimento fundou em 1940 a Convenção Batista Evangelizadora de Pernambuco, que se uniu a Convenção Batista Pernambucana em 1973, criando assim a Convenção Batista de Pernambuco, atual convenção do estado (OLIVEIRA, 2011, p.146147).

Mas a principal cisma dos Batistas no Brasil aconteceu na década de 60, fruto do movimento conhecido como Renovação Espiritual, iniciado na década de 50. Tinha como uma de suas pioneiras, a missionária Rosalee Mills Appleby (1895-1991). A intenção de Rosalee não era dividir os batistas, mas renovar sua

\footnotetext{
65 "Um germe dessa agitação chegou à Primeira Igreja Batista do Recife, em 1900, e teve um arremedo entre os batistas de Alagoas, no final de 1905..." ver mais em: OLIVEIRA, Zaqueu Moreira. Um povo chamado batista: História e princípios. 2. Ed. Revista e corrigida. Recife: Kairós Editora, 2011. p.139-147.
} 
fé. ${ }^{66}$ Mas esse movimento acabou gerando conflitos de poder e exclusão de igrejas. Primeiro na Convenção Batista Mineira, onde na assembleia de 1964 houve a exclusão de dezenas de igrejas, mas o "alvo" principal era a Igreja Batista da Lagoinha, liderada na época pelo pastor José do Rego do Nascimento. Decisão apoiada logo em seguida pela Convenção Batista Brasileira em 1965. (ALONSO, 2008)

Assim em 1967, reunidas em Belo Horizonte na igreja batista da Lagoinha, cerca de 52 igrejas excluídas criaram a hoje conhecida Convenção Batista Nacional, sob a liderança dos dois principais líderes da chamada Renovação Espiritual, Enéas Tognini (1914-2015) e José Rego do Nascimento (1922-2016).

\section{BATISTAS, IDENTIDADE E DIFERENCIAL}

\subsection{BATISTAS E A ASSEMBLÉIA DE DEUS}

Algo chama a atenção no último Censo, quase todas as igrejas evangélicas listadas caem em termos percentuais, exceto Assembleia de Deus e Batista (TEIXEIRA e MENEZES, 2013, p. 161). O que aparentemente seria só uma coincidência entre essas duas denominações, algo elas têm em comum.

O movimento pentecostal moderno tem suas origens no movimento de "santidade", influenciado pelo conceito wesleyano de perfeição cristã. Mas foi Charles Pahram que começou a defender a glossolalia ${ }^{67}$ como evidência do batismo no Espiríto Santo. Mas foi em 6 de abril de 1906, em uma reunião dirigida pelo pregador W. J. Seymour, que um menino de oito anos falou em línguas, e outras pessoas também, começando de maneira institucional o movimento pentecostal (MENDONÇA, 2002, p. 47).

Mas foi o pastor batista W. H. Durham, influenciado pelas reuniões de Seymour, que ao falar em línguas, dinfunde o que hoje é conhecido por "segunda benção". Da sua igreja sai o missionário sueco Daniel Berg, que ao passar por uma igreja batista em Belém

\footnotetext{
${ }^{66}$ OLIVEIRA, Zaqueu Moreira. Um povo chamado batista: História e princípios. 2. Ed. Revista e corrigida. Recife: Kairós Editora, 2011. p.137-148. Apud FALCÃO SOBRINHO, João. Graça transbordante. O jornal Batista, Rio de Janeiro, ano 110, n. 6, p.5, 07 fev, 2010.

${ }^{67}$ Capacidade de falar em línguas desconhecidas ou estranhas
} 
do Pará, junto com outro sueco Gunnar Vingren, funda as Assembleias de Deus em 1911. Apesar de origem pentecostal, a Assembleia de Deus tem em suas crenças e práticas, resíduos teológicos e eclesiológicos das origens históricas de seus fundadores (MENDONÇA, 2002, p. 48).

\subsection{EVANGELISMO, CONVERSÃO E PRÁXIS BATISTA}

O evangelismo é um dos grandes diferenciais dos batistas atualmente, "fazer missões" como dizem seus adeptos, faz parte do dia a dia Batista. Assim como seus fundadores que tinham uma agência de missões, eles mantêm no Brasil organizações paraeclesiástica, para treinamento, envio e manutenção de missionários, que servem no exterior e no Brasil. Podemos citar as duas maiores, a Junta de Missões Nacionais (JMN) ligada a CBB, e a Junta Administrativa de Missões (JAMI), ligada a $C B N$, as principais convenções do Brasil.

O foco evangelístico dado pelos batistas no passado, se manteve nos últimos anos. A JMN, tem atualmente 673 missionários, e diversos trabalhos sociais com fins evangelísticos espalhados pelo Brasil. ${ }^{68}$

Um desses projetos, é a Cristolândia, como é conhecido o trabalho de resgatar dependentes químicos, especialmente os viciados em crack. Nascido como resposta a Cracolândia de São Paulo, esse projeto se espalhou pelo Brasil e ganhou ampla cobertura da mídia televisiva ${ }^{69}$, como destacou o Jornal Nacional em edição do dia 05 de janeiro de $2013^{70}$.

A Cristolândia acabou levando o nome dos batistas, de maneira espontânea, as principais emissoras de TV do Brasil, atingindo grande parte da população. Isso acabou sendo utilizado como ferramenta de marketing da denominação, pois apesar de ser ligado a uma convenção (CBB) especificamente, em nenhum

\footnotetext{
${ }^{68}$ Informações do site da organização uww.missoesnacio nais.com.br.

${ }^{69}$ Os registros das diversas reportagens feitas por diversas emissoras de televisão, podem ser vistos no site do programa, http://www.cristolandia.org/vdeos.

${ }^{70}$ Pode-se acompanhar reportagem completa no link a seguir: http://g1.globo.com/jornalnacional/noticia/2013/01/lugar-conhecido-como-cristolandia-ajuda-na-recuperacao-dedependentes-de-crack-em-sp.html.
} 
momento, quando entrevistados, seus pastores e missionários tentam passar essa informação, mas sempre se dizem que é um trabalho dos batistas brasileiros.

Com uma mensagem "conversionista", alguns dos que conseguem se livrar das drogas, acabam se tornando voluntários do projeto, chegando a se tornarem missionários, multiplicando assim o trabalho dos batistas em outras cidades. Além do objetivo social e evangelístico, esse projeto dos batistas acabou se tornando uma ferramenta de crescimento denominacional.

\subsection{IGREJA AUTÔNOMAS, PASTORES PROFISSIONAIS E PLANOS DE CRESCIMENTO}

Uma das características que os batistas têm das demais igrejas da reforma é o governo congregacional. A liberdade individual, ou liberdade de expressão e crença, tão defendida pelos batistas, se mostra coletivamente na igreja local. Essa liberdade individual se volta para a liberdade da comunidade de tomar suas próprias decisões, tentando manter os princípios básicos que os identificam como batistas.

Mas apesar dessa identidade, alguns princípios têm se adaptado nas últimas décadas aos padrões modernos, principalmente nos centros urbanos, onde a exigência da igreja por resultados é maior, até porque o movimento evangélico é um movimento essencialmente urbano, como demostram as pesquisas $^{71}$.

A "profissionalização" das funções eclesiásticas, como pastores, ministros de música e missionários, é uma constante hoje em dia. Mesmo herdando o princípio da reforma do "sacerdócio universal de todo o crente", é comum ver nas igrejas batistas (como outras) pastores e ministros(as) de música serem bem remunerados, para que assim possam se dedicar totalmente a igreja (AZEVEDO, 1996, p. 18).

A autonomia da igreja exige mais ainda do pastor ou missionário. O desafio, e o desejo de multiplicar igrejas, que os primeiros missionários tiveram, hoje atinge a comunidade de

\footnotetext{
${ }^{71} 88,4 \%$ dos evangélicos de missão residem em área urbana (CAMPOS, 2013, p.148).
} 
maneira geral, ainda mais em tempos de alta taxa de crescimento evangélico no país. Hoje em dia são muitos "os planos" para fazer a igreja crescer.

Podemos citar um caso, a Igreja Batista Central de Belo Horizonte, que mudou a igreja para formato de "igreja em células"72 no início do ano 2000. Nesse ano possuía entre 200 e 500 membros, chegando em 2014 a "mais de oito mil frequentadores nas mais de mil e duzentas células". Percebe-se um objetivo numérico nesse caso (BOTTREL, 2015, p. 24-25).

Apesar da crescente pressão por crescimento numérico que atinge as igrejas evangélicas atualmente, os batistas têm mantido o foco nas pessoas "não crentes" (como são conhecidas as pessoas ou povos que não seguem a Jesus Cristo). Nisso eles se diferenciam dos neopentecostais, que têm como alvo pessoas de qualquer religião, ou que não possuam religião nenhuma.

Os batistas são sistemáticos nos seus planos de evangelização, têm sempre como objetivo abrir novas igrejas e o aperfeiçoamento doutrinário dos membros das igrejas atuais. Podemos constatar isso no atual plano de evangelização da Junta de Missões Nacionais (JMN) da CBB, chamado de Visão Brasil 2020, que quer dobrar o número de batistas até o próximo Censo ${ }^{73}$.

Como foi citado por alguns autores consultados, o governo congregacional (autonomia da igreja local) pode ter sido um fator diferencial no crescimento dos batistas nos últimos tempos. Mas não foi esse princípio de maneira isolada que deve ter levado os batistas ao continuo crescimento, pois o que dizer da igreja Congregacional, que adota o mesmo princípio de governo? É uma das menores denominações históricas de missão, e ainda foi uma das que mais caiuem números absolutos no último Censo.

O princípio de autonomia da igreja local, por si só não teria essa força, como podemos perceber no caso congregacional, mas ele aliado a uma forte defesa da identidade denominacional, a uma

\footnotetext{
${ }^{72}$ Igreja em células, são pequenos grupos de comunhão, composta de 3 a 20 pessoas no máximo. Normalmente se reúne em casas, durante a semana.

${ }^{73}$ A Convenção Batista Brasileira, com o apoio da junta de Missões Nacionais, tem um plano de crescimento chamado VISÃO BRASIL 2020. Tem a meta de atingir 2\% da população brasileira no Censo de 2020, isso seria dobrar o número atual de membros dessa convenção. Ver em: http://igrejamultiplicadora.org.br/new/visao-brasil-2020/
} 
visão evangelística, a um espírito missionário e cooperador, pode ter contribuído em muito para o contínuo crescimento dos batistas.

\subsection{MÚSICA GOSPEL, TV E O JORNAL BATISTA.}

Apesar de não ter sido objeto de estudo nas partes anteriores desse artigo, a música evangélica e a TV merecem um destaque nessa parte final. São pontos importantes para se entender o crescimento evangélico na atualidade.

A música gospel ${ }^{74}$ tem sido uma marca do evangélico moderno, os evangélicos não ouvem só os hinários comuns das igrejas, mas as bandas e cantores gospels badalados, como por exemplo o cantor e pastor batista Fernandinho e o ministério Diante do Trono da Igreja Batista da Lagoinha. As igrejas batistas de maneira geral, utilizam em sua liturgia os mais diversos instrumentos musicais, como bateria e guitarras, esses que em algumas décadas atrás não eram aceitos.

Um exemplo do uso da música como diferencial é a Igreja Batista da Lagoinha de Minas Gerais. Deles saíram o grupo conhecido como Diante do Trono, um dos grupos de música gospel mais conhecidos no Brasil. A Lagoinha uma das maiores igrejas batistas do Brasil, tem templo moderno, utiliza as redes sociais e transmitem seus cultos ao vivo. Possui Rádio e TV própria e estima ter 72 mil membros $^{75}$.

Um outro exemplo, mas no campo das mídias impressas, é O Jornal Batista, o semanário confessional informativo da CBB, um dos mais antigos do Brasil fundado em 1901. Ele é um exemplo de mídia que se adaptou aos tempos digitais, apesar de até hoje ter tiragem em papel, mas é pelo meio digital onde atinge seu maior público, além de ter todo o acervo digitalizado para consulta. ${ }^{76}$

\footnotetext{
${ }^{74}$ A Fundação Renascer, ligada à lgreja Renascer, é detentora da patente da marca gospel no Brasil (MARIANO, 2005, p.102).

${ }^{75}$ Número registrado na revista eletrônica ATOS, disponível em: http://lagoinha.com/lagoinha-wp-site/wp-content/uploads/2016/11/AH46.pdf

${ }^{76}$ http://unw.batistas. com/o-jornal-batista/acervo-digital
} 
O uso das mídias, como TV e rádio, foi e é um dos recursos mais utilizados pelos pentecostais e neopentecostais para atrair mais adeptos (MARIANO, 2005), elas têm alugado horário nas principais redes de TV do país, chegando até a possuir TV própria como a IURD (Igreja Universal do Reino de Deus).

Estratégia de mídia começou a ganhar força na década de 1970, e os batistas marcaram presença nessa época, com um programa chamado "Reencontro" apresentado pelo pastor batista Nilson Fanini na TV Educativa do Rio de Janeiro, mas retransmitida para todo o país (CUNHA, 2007, p.60).

Envolvido em polêmicas devido a seu relacionamento com a alta cúpula militar, o pastor Fanini acabou ganhando uma concessão de um canal de TV na década de 1980, comemorado pelos batistas na época, acabou sendo vendida pelo pastor. Sem nunca ter pertencido juridicamente aos batistas, esse episódio foi esquecido pela denominação. Em 1999 alguns líderes batistas promoveram outro projeto chamado "Batistas na Televisão", que acabou não vingando (CASTRO et al., 2016)

Os batistas desenvolvem ministérios de louvor, utilizam internet e mídias sociais, apesar de ser uma denominação histórica, com forte identidade na defesa da ética e da moral, notase que é uma denominação contextualizada com os tempos modernos.

Vimos existir um protagonismo dos batistas nessas áreas em relação as demais denominações protestantes históricas de missão, mas como não temos dados suficientes, essa informação não nos assegura dizer que isso contribuiu significativamente para o crescimento dos batistas. 


\section{CONSIDERAÇÕES FINAIS}

Governo congregacional, cooperação na missão, foco evangelístico, forte identidade denominacional e uso dos modernos meios de comunicação, aspectos e princípios importantes na formação dos batistas e de seu crescimento.

Percebemos que não foi só por estratégias recentes que os batistas se mantiveram crescendo nas últimas décadas, mesmo com percentuais menores que outros grupos, como os pentecostais, por exemplo. Vimos que decisões históricas dos batistas dão frutos até hoje, como o foco evangelístico dos primeiros missionários. Os batistas apesar da diversidade de igrejas, grupos e convenções tem conseguido manter a sua identidade nacionalmente.

O governo congregacional, aliado a alguns aspectos citados anteriormente, merece um destaque nesse diferencial batista para o crescimento. Interessante observar, que apesar dessa autonomia, as igrejas "defendem" a denominação e têm orgulho de pertencer a ela.

Apesar de ter uma doutrina firme, com alguns princípios que os diferenciam das demais igrejas de missão, como o governo e o batismo, eles não têm influência direta no crescimento, mas sim na afirmação da identidade desse grupo.

E com o passar dos anos do último Censo, esses números podem ter oscilado tanto para cima como para baixo, mas se seguir a tendência das últimas décadas, os batistas tendem a crescer mais ainda, isso é um desafio para as demais igrejas históricas de missão, diminuir esse protagonismo dos batistas. 


\section{REFERÊNCIAS}

ARAÚJO, Julia Silveira; REFKALEFSKY, Eduardo. Comunicação e contracultura religiosa: o crescimento da Igreja Batista no Brasil. In: Congresso de Ciências da Comunicação na Região Sudeste, 16, Rio de Janeiro. 2009. Disponível em: http://www.intercom.org.br/papers/regionais/sudeste2009/resum os/R14-0294-1.pdf. Acesso em: 07 abril 2016.

ALONSO, Leandro Seawright. Poder e experiência religiosa: Uma história de um cisma pentecostal na Convenção Batista Brasileira na década de 1960. 2008. 209f. Dissertação de mestrado. Faculdade de Filosofia e Ciências da Religião da Universidade Metodista de São Paulo, São Bernardo do Campo, 2008.

ANTONIAZZI, Alberto. Porque o panorama religioso mudou tanto? Revista Horizonte. Belo Horizonte, v3, n 5, p. 13-39, 2 o sem., 2004.

AZEVEDO, Israel Belo de. A celebração do indivíduo: A formação do pensamento batista brasileiro. Piracicaba: Unimep; São Paulo: Êxodos Editora, 1996.

BOTTREL, Roberto. Multiplicação: o desafio do cristão, da liderança, e da igreja. Belo Horizonte: 3i Editora, 2015.

CAMPOS, Leonildo Silveira. Os mapas, atores e números da diversidade religiosa cristã brasileira: Católicos e evangélicos entre 1940 e 2007. Revista de Estudos da Religião. São Paulo, vol. 4, p. 9-47, dezembro, 2008.

Evangélicos de missão em declínio no Brasil.

In: TEIXEIRA, Faustino; MENEZES, Renata (orgs.). Religiões em movimento: o censo de 2010. Petrópolis: Editora Vozes, 2013, p. 127-160.

CASTRO, Alexandre de Carvalho; DUSILEK, Sérgio Ricardo Gonçalves e SILVA; Clemir Fernandes. Identidade social, mídia televisiva e construção histórico-cultural da memória coletiva: - caso de um movimento sociorreligioso no Brasil. Relig. soc. [online]. 2016, vol.36, n.1, p.74-102. Disponível em: <http://www.scielo.br/scielo.php?script=sci_arttext\&pid=S0100$85872016000100074 \&$ Ing=pt\&nrm=iso\&tlng=pt.> Acesso em: 07 abril 2016. 
CONVENÇÃO BATISTA BRASILEIRA. Convenção batista brasileira: Valorizando a nova geração. Rio de Janeiro, 2013.

CRABTREE, A. R. História dos batistas no Brasil até o ano de 1906. 2 Ed. Rio de Janeiro: Casa Publicadora Batista, 1962.

CUNHA, Magali do Nascimento. A explosão gospel: um olhar das ciências humanas sobre o cenário evangélico no Brasil. Rio de Janeiro: MAUAD Editora: Instituto Mysterium, 2007.

INSTITUTO BRASILEIRO DE GEOGRAFIA E ESTATístiCA. Censo demográfico 1991: Resultados preliminares. Rio de Janeiro, IBGE, 1992.

Censo demográfico 2000: Característica gerais da população/resultados das amostras. Rio de Janeiro, IBGE, 2003.

. Censo demográfico 2010: Característica gerais

da população, religião e pessoas com deficibencia. Rio de Janeiro, IBGE, 2012.

JACOB, Cesar Romero; HEES, Dora Rodrigues; WANIEZ, Philippe. Religião e território no Brasil, 1991-2010. Rio de Janeiro: Editora PUC-Rio, 2013.

et al. Atlas da filiação religiosa e indicadores sociais no Brasil. Rio de Janeiro: Editora PUC-Rio; São Paulo: Edições Loyola, 2003.

LÉONARD, Émile G. O protestantismo brasileiro: estudo de eclesiologia e história social. 3 ed. Rev. São Paulo: ASTE, 2002.

MARIANO, Ricardo. Neopentecostais: Sociologia do novo pentecostalismo no Brasil. 2 ed. São Paulo: Edições Loyola, 2005.

Mudanças no campo religioso no censo 2010.

Debates do NER. Porto Alegre, ano 14, n. 24, p. 119-137, jul. /dez., 2013.

MARIZ, Cecília L.; GRACINO JR, Paulo. As igrejas pentecostais no censo de 2010. In: TEIXEIRA, Faustino; MENEZES, Renata (orgs.). Religiões em movimento: o censo de 2010. Petrópolis: Editora Vozes, 2013, p. 161-174. 
MATOS, Alderi Souza de. Breve história do protestantismo no Brasil. Goiânia, v.3, n.1, 2011. Disponível em: <http://www.faifa.edu.br/revista>. Acesso em: 01 abril 2016.

MENDONÇA, Antônio Gouvêa; VELASQUES FILHO, Prócoro. Introdução ao protestantismo no Brasil. 2 ed. São Paulo: Edições Loyola, 2002.

- República e pluralidade religiosa no

Brasil. Revista USP. São Paulo, n. 59, p. 144-163, setembro/novembro, 2003.

Protestantismo no Brasil: Um caso de religião e cultura. Revista USP. São Paulo, n. 74, p. 160-173, julho/agosto, 2007.

O protestantismo no Brasil e suas encruzilhadas. Revista USP. São Paulo, n. 67, p. 48-67, setembro/novembro, 2005.

MESQUITA, Antônio N. de. História dos batistas no Brasil: de 1907 a 1935. Rio de Janeiro: Casa Publicadora Batista, 1962.

MOORE, Waylon B. Multiplicando discípulos: o método neotestamentário para o crescimento da igreja. Rio de Janeiro: Convicção, 2015.

NERI, Marcelo Cortês. Novo mapa das religiões. Rio de Janeiro: FGV, 2011.

OLIVEIRA, Zaqueu Moreira. Um povo chamado batista: História e princípios. 2. Ed. Revista e corrigida. Recife: Kairós Editora, 2011.

Princípios e práticas batistas: Uma abordagem histórica aplicada aos nossos dias. 4. Ed. Revista e ampliada. Recife: Kairós Editora, 2014.

A palavra crescia poderosamente: 80 anos de crescimento dos batistas de Pernambuco. Recife: Kairós Editora, 2010.

Liberdade e exclusivismo: Ensaios sobre os batistas ingleses. Rio de Janeiro: Horizontal Editora, 1997.

PEREIRA, José Reis. História dos Batistas no Brasil: 1882-1979. Rio de Janeiro: JUERP, 1982. 
Janeiro:JUERP, 1979.

Breve História dos Batistas. 2 Ed. Rio de

ROCHA, Daniel; ZORZIN, Paola. Os evangélicos em números: algumas observações sobre o que revelou (e o que não revelou) o estudo "Novo Mapa das Religiões" sobre o "agregado evangélico brasileiro". V.13, 2012. Disponível em: <http://www.abhr.org.br/plura>. Acesso em: 01 abril 2016.

SILVA, Roberto do Amaral. Princípios e doutrinas batistas. Rio de Janeiro, JUERP, 2003.

SOUZA, Sócrates Oliveira de (orgs.). Pacto e Comunhão: documentos batistas. Rio de Janeiro: Editora Convicção, 2010.

SOUZA, Alverson. Thomas Jefferson Bowen: o primeiro missionário batista no Brasil. Rio de Janeiro: Editora Novos Diálogos, 2012. 